\title{
Slik blir pasienter med prostatakreft mer tilfreds med informasjonen
}

\section{Menn med prostatakreft trenger realistisk informasjon, og det kan erfarne sykepleiere gi dem.}

Monica Skoglund Bratlie

Sykepleier og fagutviklingssykepleier

Avdeling for urologi, Oslo universitetssykehus, Aker

Arnhild Fredriksen

Uroterapeut og spesialsykepleier

Avdeling for urologi, Oslo universitetssykehus, Aker

\section{Sykepleie \\ Preoperativ informasjon \\ Opplæring \\ Kreft \\ Pasienttilfredshet}

Sykepleien 2019107 (77737) (e-77737)

DOI: 10.4220/Sykepleiens.2019.77737

\section{Hovedbudskap}

Pasienter med prostatakreft har behov for mye informasjon. Vårt prosjekt viste at preoperativ informasjon og opplæring om sykdom og behandling gitt av erfarne sykepleiere ga tilfredse pasienter.

Bakgrunnen for artikkelen er en spørreunders $\varnothing$ kelse som ble utført på menn som ble operert for prostatakreft i 2010-2011. Vi ønsket å unders $\varnothing$ ke om pasientene var tilfredse med informasjonen før behandlingen for prostatakreft med robotassistert laparoskopisk prostatektomi (RALP). 
En betydningsfull faktor for tilfredshet hos pasienter som skal opereres, er å få relevant informasjon før behandling og prosedyrer (1).

Personalet ved avdeling for urologi på Aker, Oslo universitetssykehus (OUS) har kontinuerlig utviklet og forbedret tilbudet til pasienter som skal opereres for prostatakreft. Prostatakreft er den hyppigste kreftformen blant menn i Norge. I 2017 fikk 4991 menn diagnosen, og 90 prosent av tilfellene oppstår etter fylte 60 år.

\section{$\equiv$ ¿Prostatakreft er den hyppigste kreftformen blant menn i Norge.»}

Prostatakreft er meget sjelden hos menn under 45 år (2).

$\varnothing \mathrm{kning}$ i levealder og tidligere diagnose har ført til en kraftig $\varnothing$ kning i antall menn som lever med prostatakreft. Antallet er doblet på ti år, fra 25907 i 2007 til 49718 i 2017 (3).

I Norge praktiseres det i hovedsak to typer kurativ behandling for prostatakreft: strålebehandling og radikal prostatektomi $(\mathrm{RP})$.

\section{Radikal prostatektomi}

Radikal prostatektomi (RP) er etablert behandling med kurativ målsetning. $\mathrm{RP}$ innebærer fjerning av hele prostata med urethra pars prostatae og begge sædblærer. Inngrepet kan utføres med åpen tilgang, men gjøres i økende grad med robotassistert laparoskopi.

Kilde: onkolex.no

Ved vår avdeling tilbys robotassistert laparoskopisk prostatektomi (RALP), og metoden har utviklet seg betydelig de siste årene. RALP gir redusert postoperativ smerte, reduserer peroperativ blødning og forkorter pasientens liggetid på sykehus $(4,5)$.

Pasientene må informeres om at utfallet av behandlingen kan føre til betydelige endringer i livskvaliteten (6). For å forberede pasienten på endringer i livskvaliteten postoperativt er informasjon og opplæring en vesentlig del av det preoperative tilbudet til pasienten. 
Informasjonen skal hjelpe pasientene til å leve med og mestre både korttids- og langtidssymptomene etter RALP.

Kunnskap om plagsomme ettervirkninger som urinlekkasje og ereksjonssvikt kan føre til at pasienten velger å ikke la seg behandle, eventuelt velger noen en behandling som ikke er tilstrekkelig dokumentert til å kunne inngå i ordinært behandlingstilbud, eller pasienten utsetter operasjonen dersom det er tilrådelig $(7,8)$.

\section{Hva sier loven?}

Viktigheten av informasjon til pasienter gjenspeiles i lovverk, brukerunders $\varnothing$ kelser og nasjonale strategier. If $\varnothing$ lge pasientrettighetsloven $\S 3-2$ har pasienten «[...] rett til medvirkning når det gjelder valg av tilgjengelige og forsvarlige behandlingsmetoder og informasjon som er nødvendig for å få innsikt i sin helsetilstand og innholdet i helsehjelpen» (9).

I helsepersonelloven § 10 står det «at pasienten i tillegg skal informeres om mulige risikoer og bivirkninger knyttet til behandling» og at «vi som helsepersonell skal så langt det er mulig sikre oss at mottakere av informasjonen har forstått innholdet og betydningen av opplysningene» (10).

\section{Gjør kloke valg}

«Choosing Wisely» er en kampanje som startet i USA i 2012 og dreier seg om å unngå overbehandling (11). Kampanjen har spredt seg til mange land, og høsten 2018 ble «Gjør kloke valg» - kampanjen startet av legeforeningen i Norge (12).

Legen er ansvarlig for forsvarlig behandling, men med dialog og forståelig informasjon vil pasienten og legen kunne foreta et «samvalg» om beste behandlingsmetode (13-15). Informasjonen må tilpasses den enkelte, og spesielt til dem som har $\varnothing \mathrm{kt}$ risiko for bivirkninger etter RALP. Eldre over 65 år, personer med høy BMI, pasienter som har hatt tidligere prostataoperasjon eller menn med stor prostata har $\varnothing \mathrm{kt}$ risiko for bivirkninger (16). 


\section{Kurs for pasienter}

I lov om spesialisthelsetjenesten, som trådte i kraft fra 1. januar 2001 (17), står det at opplæring av pasienter og pårørende er en av sykehusets hovedoppgaver, og samme år startet vår avdeling et kurstilbud for prostatakreftpasienter og pårørende.

Kursene ble gjennomført på vårt lærings- og mestringssenter og ble holdt av sykepleiere, kreftsykepleiere, uroterapeuter og leger fra vår avdeling. Representanter fra Kreftforeningen og pasientorganisasjonene Norsk forening for personer med urologiske sykdommer (NOFUS) og Prostatakreftforeningen (PROFO) holdt også innlegg.

De første kursene foregikk på kveldstid, etter hvert foregikk kursene på dagtid fordi vi anså kursene som en del av behandlingstilbudet. Målsettingen var at deltakerne på kursene skulle få økt kunnskap om sin nye livssituasjon og få hjelp til å mestre problemer som kunne oppstå. De fikk også kontakt med pasientorganisasjonene som presenterte seg og sitt arbeid.

\section{三 «Vi fikk gode tilbakemeldinger fra kursdeltakerne, men også innspill om at de hadde ønsket mer informasjon preoperativt.»}

Kurspakken besto av fire samlinger à tre timer.

Undervisningsformen på kursene var dialog mellom foredragsholdere og kursdeltakere samt gruppearbeid.

Kursene ble oppdatert og utviklet i henhold til ny kunnskap, trygderettigheter og etter evaluering fra deltakerne.

Vi fikk gode tilbakemeldinger fra kursdeltakerne, men også innspill om at de hadde $\varnothing$ nsket mere informasjon preoperativt.

\section{Uroterapeut gir opplæring}

Langt fra alle pasienter som skulle til RALP, deltok på kursene. For å im øtekomme tilbakemeldingene fra kursdeltakerne og sikre at alle fikk mer informasjon startet vi i 2004 det nye tilbudet med preoperativ informasjon og opplæring hos uroterapeut. 
Det nye tilbudet ble etter hvert innarbeidet i vår faste preoperative rutine, som inneholder legeunders $\emptyset$ kelse, samtale med anestesilege og sykepleier fra urologisk sengepost og prøvetaking av pasienten. På grunn av stort antall RALP-operasjoner ble det nødvendig at også vår kreftsykepleier, i tillegg til uroterapeut, kunne gjennomføre den preoperative opplæringen.

Etter innføring av det nye tilbudet opplevde vi at færre pasienter meldte seg på kursene, sannsynligvis fordi de fikk mer individuell informasjon og opplæring på forhånd.

Vi avsluttet derfor vårt kurstilbud, men informerte om andre kursmuligheter i regi av Prostatakreftforeningen (PROFO), Kreftforeningen, Montebellosenteret og Norsk forening for personer med urologiske sykdommer (NOFUS).

\section{Ulikt behov for informasjon}

Vi har erfart at å fordøye og forstå all informasjon som blir gitt når du nylig har fătt en kreftdiagnose, kan være vanskelig.

Sitat fra en pasient: «Det var godt kona mi var med, for hun fikk med seg mye mer enn meg. Jeg hørte legen sa jeg hadde kreft, men husker nesten ikke mer fra den samtalen.»

Skalla og medarbeidere viser at selv om mange pasienter er relativt forn $\varnothing \mathrm{yd}$ med informasjonen de får, ønsker de likevel mer. Informasjonsbehovet er varierende og avhenger blant annet av pasientenes følelser, motivasjon og mestringsmåte, stress og engstelse (18).

Davidson og Mills påpeker at det er forskjell på hvor tilfredse pasienter med forskjellige kreftdiagnoser er med informasjonen de får. Pasienter med prostatakreft er mindre tilfredse med informasjonen enn andre (19).

\section{Nyttig hefte}

Når diagnosen er stilt, får pasientene vårt et hefte om RALP, som er utarbeidet i samarbeid med sykepleiere på avdeling for urologi på Radiumhospitalet OUS. Heftet inneholder informasjon om blant annet hva operasjonen innebærer, om bruk av blærekateter og mulige ettervirkninger av operasjonen. 
Vår erfaring er at pasientene sier at heftet gir god informasjon. Vi opplever likevel at det er nødvendig å gå grundig igjennom innholdet i heftet under opplæringen med uroterapeut eller kreftsykepleier.

\section{Hva lærer pasienten?}

I vår studie var det uroterapeut som ga informasjon og opplæring (20).

Opplæringen varer cirka en time og omhandler anatomi og fysiologi, og vi legger vekt på informasjon om følgende:

- operasjonen

- permanent urinkateter, hvordan det ser ut, funksjon og kateterstell

- kontinensmekanismer. Normal blærefunksjon og hvordan kontinensmekanismene kan påvirkes av operasjonen

- bekkenbunnstrening - praktisk veiledning og skriftlig instruksjon

- ulike innlegg/bleietyper for menn

- normalfunksjon med ereksjon, ejakulasjon og orgasme og hvordan funksjonen kan påvirkes av operasjonen

- postoperativ ereksjonsfremmende behandling

- tarmfunksjon og luftsmerter

- postoperativ aktivitet

- oppfølging, kontroller, pasientforeninger og kurstilbud

\section{Kontinensmekanismer}

De nedre urinveier hos menn består av urinblære, prostata og urinrør. Evnen til å holde på urinen opprettholdes når kontinensmekanismen er intakt.

Vi snakker om passiv og aktiv kontinens. Den passive kontinensen opprettholdes av den glatte muskulaturen i urinrøret, mens den aktive blir opprettholdt av tverrstripet lukkemuskulatur (sfinkter). Denne komplekse mekanismen kan skades i forbindelse med en prostataoperasjon og føre til ufrivillig urinlekkasje (21).

\section{Realistiske forventninger}

Målet med den preoperative informasjonen og opplæringen er å gi pasientene konkret muntlig og skriftlig informasjon som kan skape realistiske forventninger om hva de kan oppleve postoperativt. Dette kan bidra til å redusere angst og usikkerhet om problemer som kan oppstå (22). 


\section{«Pasienten har fått våre telefonnumre og kan ta kontakt ved behov.»}

Pasienten får tilbud om å ha med ektefellen eller annen nær person både til opplæringen og til behandlingen postoperativt. Tilbakemeldinger fra våre pasienter og pårørende viser at det er viktig å ha mulighet til å kunne ta kontakt for ytterligere opplæring, behandling og oppfølging postoperativt. Pasienten har fått våre telefonnumre og kan ta kontakt ved behov. I tillegg er vår rutine også å ringe pasienten 7-14 dager etter at blærekateteret er fjernet, for å høre hvordan han har det.

\section{Metode, utvalg og data}

Hensikten med spørreundersøkelsen var å få vite hvor tilfredse pasientene var med informasjonen de fikk preoperativt, og vi ønsket mer kunnskap om hvordan de hadde det postoperativt. Dette for å se om det var samsvar med vår informasjon og pasientenes opplevelser.

Data ble innhentet fra to ulike spørreskjema postoperativt, etter 14 dager og seks måneder. Data fra 14 dagers skjemaet er også benyttet i førsteforfatters masteroppgave ved Universitetet i Oslo i 2015 (23).

Studien hadde kvantitativt deskriptivt design. Utvalget besto av pasienter som ble RALP-operert i perioden mars 2010 til mai 2011. Inklusjonskriterier: operert ved vårt sykehus og undertegnet samtykkeskjema. Eksklusjonskriterier: pasienter som ikke kunne norsk språk, eller ikke hadde hatt preoperativ opplæring.

Deltakerne ble rekruttert til studien cirka 14 dager etter operasjonen. De fikk spørreskjemaet utdelt enten på poliklinikken når blærekateteret ble fjernet, eller de fikk skjemaet tilsendt i posten dersom de fjernet kateteret ved et annet sykehus. Deltakerne skulle besvare spørreskjema, signere samtykkeskjema og returnere disse i en frankert svarkonvolutt. Spørreskjemaet «etter seks måneder» ble tilsendt i posten. Purrebrev ble sendt ut én gang.

\section{Spørreskjema og analyse}


Det ble ikke funnet spørreskjema som egnet seg til studien. Skjemaene ble derfor utviklet lokalt, ikke pilottestet før studien ble satt i gang, og de er ikke validert. Skjemaene inneholdt spørsmål om forventninger til plager/ubehag ut fra gitt informasjon samt spørsmål om hva de opplevde av plager/ubehag og generell tilfredshet med informasjon og behandling.

Spørsmålet om tilfredshet med informasjon er rangert fra 1-5:

1 = svært misforn $\varnothing y d$

2 = ganske misforn $\varnothing y d$

$3=$ middels

4 = ganske forn $\varnothing \mathrm{yd}$

5 = svært forn $\varnothing \mathrm{yd}$

Det var også et kommentarfelt med mulighet til å utdype synspunkter og opplevelser.

(tabell 1)

Spørsmålene om forventede og opplevde plager er gradert på en Likert-skala med skår fra

O-10:

$\mathrm{O}=$ ingen $/$ ikke i det hele tatt og

10 = i svært stor grad

Datamaterialet er analysert ved hjelp av analyseverktøyet SPSS (Statistical

Package for the Social Sciences).

\section{Resultater}

Demografiske karakteristika: 232 pasienter fikk utdelt spørreskjemaet. 191 pasienter svarte på «14-dagersskjemaet» (82,3 prosent), og 183 pasienter svarte på «6månedersskjemaet» (78,9 prosent).

Gjennomsnittsalderen på pasientene var 62,5 år med en spredning fra 43 til 74 år. De fleste var gift eller hadde samboer eller partner (87,5 prosent). Over halvparten av pasientene hadde høyere utdanning (58,9 prosent), og over halvparten av pasientene var yrkesaktive (56,9 prosent).

Tilfredshet med informasjon etter pasientens karakteristika: Av variablene alder, sivilstatus, utdanning og arbeid var det kun alder som var statistisk signifikant. Eldre pasienter var mer forn $\varnothing y d$ med informasjonen enn yngre $(p<0,001)$. 
Tabell 1. Pasientene svarte på spørsmålet: Totalt sett- hvor fornøyd er du med informasjonen du har fått?

\begin{tabular}{lcccc}
\hline & $\begin{array}{l}14 \text { dager } \\
\mathbf{N}=190\end{array}$ & $\%$ & 6 mnd & \\
& 2 & 1,0 & $\mathbf{N}=183$ & 0,5 \\
Svært misfornøyd & & & 1 & 6,0 \\
Ganske misfornøyd & 17 & 39,9 & 11 & 13,7 \\
Middels & 75 & 50,3 & 25 & 43,7 \\
Ganske fornøyd & 96 & 0,5 & 66 & 36,1 \\
Svært fornøyd & 1 & 100,0 & 183 & 100,0 \\
Ikke svart & 191 & & & \\
Total & & & & \\
\hline
\end{tabular}

\section{Hva mener pasientene?}

I «14-dagersskjemaet» utdypet 68 pasienter hva de syntes om den preoperative opplæringen og informasjonen. De fleste kommentarene var av positiv karakter. Pasientene mente opplæringen og informasjonen var realistisk, nyttig og god, og at den ble gitt med et klart og forståelig språk.

\section{三 «De fleste kommentarene var av positiv karakter.»}

Noen skrev at informasjonen hadde en beroligende effekt i en situasjon preget av usikkerhet. Selv om mange pasienter virket fornøyde, kommenterte noen at det var mye informasjon på kort tid, og at den kunne vært mer individuelt tilpasset. Et tema som kom tydelig frem, var knyttet til blærekateter og kateterproblematikk.

Noen pasienter $\varnothing$ nsket mer konkret og utdypende informasjon, og i tillegg ønsket de å få økt oppfølging postoperativt. I «6-månedersskjemaet» var det ikke mange fritekstkommentarer. Pasientene beskrev stort sett samme plager som de hadde opplevd tidligere postoperativt.

Fritekstkommentarene fra pasientene omhandlet plager med blærekateteret som blod i urinen, svie og smerte ved vannlating, urinveisinfeksjon, urinlekkasje ved aktivitet og hyppig vannlating. I tillegg kommenterte noen pasienter at de hadde mage- og luftsmerter, smerter i penis, vondt i skrittet, trykk mellom endetarm og pung.

På spørsmålet «Var timen med opplæring og informasjon hos uroterapeut nyttig?» svarte 189 av 191 pasienter.

Gjennomsnitt på pasientenes skår på en Likert-skala fra o-10 var 8,4. Høyere tall betyr at opplæringen var nyttig. 
På spørsmålet «Har informasjonen du fikk før operasjonen stemt med det du har opplevd etterpå?» svarte 183 av 183.

Gjennomsnitt på pasientenes skår på en Likert-skala fra o-10 var 7,6 .

Tabell 2. Forskjell i gjennomsnitt på pasientenes skåre (0-10) om hva de forventet å oppleve ut fra informasjon og hva de faktisk opplevde etter $6 \mathrm{mnd}$. ( $\mathrm{N}=183)$. Lavere tall betyr mindre plager.

\begin{tabular}{cccc}
\hline $\begin{array}{c}\text { Forventet plager } \\
\text { urinlekkasje }\end{array}$ & $\begin{array}{c}\text { Opplevd plager } \\
\text { urinlekkasje }\end{array}$ & $\begin{array}{c}\text { Forventet plager } \\
\text { ereksjon }\end{array}$ & $\begin{array}{c}\text { Opplevd plager } \\
\text { ereksjon }\end{array}$ \\
$\mathrm{N}=183$ & $\mathrm{~N}=183$ & $\mathrm{~N}=183$ & $\mathrm{~N}=183$ \\
3,473 & 3,201 & 5,317 & 7,378 \\
\hline
\end{tabular}

\section{Diskusjon}

Studien viste at 50,3 prosent av pasientene var svært forn $\varnothing y d$ med informasjonen som ble gitt preoperativt. Kun 1 prosent av pasientene var svært misfornøyd. Etter seks måneder var 36,1 prosent svært forn øyde, mens 6 prosent var ganske misforn $\varnothing y d e, ~ o g ~ 0,5$ prosent av pasientene var svært misfornøyde. Se tabell 1.

På spørsmålet om informasjonen pasientene fikk før operasjonen stemte med det de opplevde etterpå, var det godt samsvar. I likhet med andre studier skårer eldre høyere på pasienttilfredshet enn de som er yngre $(24,25)$.

Pasienter har varierende behov for informasjon, men behovet blir ofte ikke oppfylt (18). Vår studie viste at pasientene skåret høyt på nytteverdien av informasjon og opplæring hos uroterapeut.

Siden informasjonsbehovet er så individuelt, er det en utfordring å gi den enkelte tilfredsstillende informasjon. Jaeger og medarbeidere konkluderer med at pasienter bør få en basisinformasjon for den aktuelle behandling, og at tilleggsinformasjon bør gis til dem som har behov for det (26). Ifølge Bjertnes og medarbeidere er oppfylte forventninger en signifikant faktor for tilfredshet (27).

En pasient som var svært misfornøyd med informasjonen, skrev i en fritekstkommentar:

«Jeg fikk ikke noe alternativ til behandling. Det ble informert om at operasjon skulle utføres. Jeg visste ikke at det var andre muligheter. Timen hos uroterapeut er jeg svært fornøyd med, men skulle $\varnothing n s k e$ at den timen var tidligere i prosessen.» 
«Jeg fikk valget mellom ‘å se det litt an' [vente og se] samtidig som de sa jeg var heldig fordi man hadde oppdaget kreften så tidlig at man kunne operere den bort. Det ble krysspress mellom å vente [risikere at kreften ble større og spredde seg] og operasjon.»

\section{Aktiv overvåkning}

Det er en stor påkjenning for pasienter å vite om at de har kreft, og at de er redd for spredning. For å unngå overbehandling og komplikasjoner etter behandling blir pasienter med lavrisikokreft anbefalt å avvente operasjon i første omgang. I en slik situasjon er det viktig med oppdatert, kvalifisert og trygg informasjon både fra urolog og onkolog, og pasienten må få regelmessig oppfølging, såkalt «aktiv overvåkning».

Vi må trolig også ta i betraktning at pasienter med prostatakreft som venter på operasjon, er engstelige, og at det kan påvirke hvordan de oppfatter informasjonen om hva de kan forvente i behandlingsforløpet (28).

Kjente komplikasjoner etter operasjonen er urinlekkasje og ereksjonssvikt, som kan oppleves i større eller mindre grad $(6-8,28)$.

Vår studie viser at gjennomsnittet av pasientene forventet mere urinlekkasje enn opplevd, mens opplevde ereksjonsplager var høyere enn forventet (tabell 2). Urinlekkasjen bruker gradvis å bli mindre i løpet av det første året, men det er umulig å si eksakt hvor stor den blir, eller hvor lenge den vil vare. Noen få har full kontroll over vannlatingen like etter kateterfjerning. Vi må likevel forberede pasientene på komplikasjonen og ikke minst tilby hjelp postoperativt.

\section{Kan påvirke seksuallivet}

Pasienten må også få realistisk informasjon om risikoen for ereksjonssvikt, og at ereksjonsevnen ikke blir som før. Hvis vi ordlegger oss slik at han får en oppfatning av at alt vil rette seg til slik det var før operasjonen, kan resultatet bli en utilfreds pasient fordi forventninger ikke blir oppfylt (26). 
En bivirkning pasienten også må kjenne til, er risiko for urinlekkasje i forbindelse med seksuell aktivitet, og at det ikke er uvanlig eller farlig. Han kan også oppleve smertefull orgasme (29). Hvis han eller paret ikke er forberedt på dette, kan det resultere i at de unngår all seksuell kontakt, og medføre redusert livskvalitet $(28,29)$. Vi må imidlertid være klar over at ikke alle er mottakelige for å snakke om seksuell aktivitet på dette tidspunktet.

\section{三 «Ereksjonssvikt kan være et følsomt tema for mange.»}

Erfaringsmessig er hovedfokuset til pasienten å bli «kvitt kreften», og de ønsker heller å komme tilbake til temaet om ereksjon og samliv senere i forløpet. Likevel må temaet belyses for å kunne kartlegge i hvilken grad operasjonen har påvirket denne funksjonen. Ereksjonssvikt kan være et følsomt tema for mange, men det må inkluderes i basisinformasjonen hos alle (28).

Ikke uventet så vi at pasienter som var misfornøyd med informasjonen og behandlingen etter seks måneder, hadde stor urinlekkasje og total ereksjonssvikt. Men vi så også at noen til tross for stor urinlekkasje og total ereksjonssvikt var svært forn øyd både med informasjon og behandling. Det kan være vanskelig for pasientene å klare å skille mellom tilfredshet med informasjon og tilfredshet med utfallet av behandlingen (28).

\section{Konklusjon}

Vår erfaring er at denne pasientgruppen trenger realistisk og individuell informasjon og opplæring preoperativt og god postoperativ oppfølging.

Komplikasjonene urinlekkasje og ereksjonssvikt, som er sterkt forbundet med redusert livskvalitet, må være med i basisinformasjonen. Det må være en prioritert oppgave å identifisere de mennene som er mest utsatt for å kunne få ereksjonssvikt etter operasjonen, og gi dem realistisk informasjon preoperativt.

Studien viste at informasjon om kateter, kateterproblematikk og luftsmerter også må være et prioritert tema. Det at erfarne sykepleiere med spesialkunnskap om både sykdom og behandling bidrar med preoperativ informasjon og opplæring vil sannsynligvis kunne dekke mer av pasientenes og pårørendes informasjonsbehov. 
Pasientene i vår studie var veldig tilfreds med informasjon og opplæring fra uroterapeut i tillegg til vår faste preoperative rutine. Modellen vi har fulgt, kan overføres til andre diagnosegrupper.

I tillegg må vi sørge for at muntlig og skriftlig informasjon til enhver tid er av høy kvalitet og oppdatert i henhold til ny kunnskap om gjennomføring av behandling og risiko for bivirkninger.

Takk for veiledning og hjelp til professor dr.med. Lars Magne Eri, dr.ph. i sykepleie May Solveig Fagermoen, tidligere

førsteamanuensis ved avdeling for sykepleievitenskap UiO og forskningssykepleier Gro Boezelijn.

\section{Referanser}

1. Krupat E, Fancey M, Cleary PD. Information and its impact on satisfaction among surgical patients. Soc Sci Med. 2000;51(12):1817-25.

2. Kreftforeningen. Prostatakreft. Oslo; 01.06.2019. Tilgjengelig fra: https://kreftforeningen.no/omkreft/kreftformer/prostatakreft/ (nedlastet 21.06.2018).

3. Kreftregisteret. Prostatakreft. Oslo; 27.06.2019. Tilgjengelig fra: https://www.kreftregisteret.no/Generelt/Omkreft/Prostatakreft/ (nedlastet 27.06.2019).

4. Johnson I, Ottosson F, Lien MD, Berg RE, Hoff J-R, Wesswl N, et al. Switching from laparoscopic radical prostatectomy to robot assisted laparoscopic prostatectomy: comparing oncological outcomes and complications. Scand J Urol. 2018;52(2):116-21.

5. Du Y, Long Q, Guan B, Mu L, Tian J, Jiang Y, et al. Robotassisted radical prostatectomy is more beneficial for prostate cancer patients: a system review and meta-analysis. Med Sci Monit. 2018 januar;14;24:272-87.

6. Wallerstedt A, Nyberg T, Carlsson S, Thorsteinsdottir T, Stranne J, Tyritzis SI, et al. Quality of life after open radical prostatectomy compared with robot-assisted radical prostatectomy. Eur Urol Focus. 2019 mai;5(3):389-98. DOI: $\underline{10.1016 / j . e u f .2017 .12 .010}$ 
7. Wilt TJ, Jones KM, Barry MJ, Andriole GL, Culkin D, Wheeler T, et al. Follow-up of prostatectomy versus observation for early prostate cancer. N Engl J Med. 2017;377(2):132-42.

8. Alver A, Brun A. Kjærlig kjøter. Dagbladet, Magasinet. 05.05.2018. Tilgjengelig fra:

https://www.dagbladet.no/magasinet/kjaerlig-kjoter/69763507 (nedlastet 01.07.2019).

9. Lov 02. juni $1999 \mathrm{nr} .61 \mathrm{om}$ pasient- og brukerrettigheter (pasient- og brukerrettighetsloven). Tilgjengelig fra: https://lovdata.no/dokument/NL/lov/1999-07-02-63 (nedlastet 30.07.2019).

10. Lov 02. juni 1999 nr. 64 om helsepersonell

(helsepersonelloven). Tilgjengelig fra: https://lovdata.no/dokument/NL/lov/1999-07-02-64 (nedlastet 30.07.2019).

11. Choosing Wisely. Promoting conversations between patients and clinicians.Philadelphia: Choosing Wisely. 2019. Tilgjengelig fra: http://www.choosingwisely.org (nedlastet 30.07.2019).

12. Baugst $\varnothing$ V. Gjør kloke valg Norge rundt. Tidsskriftet. Den norske legeforening. 2019 januar; (1). Tilgjengelig fra: https://tidsskriftet.no/2019/o1/aktuelt-i-foreningen/gjorkloke-valg-norge-rundt (nedlastet 07.08.2019).

13. Westin S. Må pasienter selv ta «kloke valg»? Aftenposten. 02.08.2018. Tilgjengelig fra:

https://www.aftenposten.no/meninger/kronikk/i/wEj31L/Mapasienter-selv-ta-kloke-valg--Steinar-Westin (nedlastet 01.07.2019).

14. Hansen EE. Et underkommunisert problem. Aftenposten. 05.08.2018.

15. St $\varnothing$ rdal K. Vi overlater ikke ansvaret til pasientene. Aftenposten. 08.08.2018. Tilgjengelig fra: https://www.aftenposten.no/meninger/debatt/i/9mAxRp/Vioverlater-ikke-ansvaret-til-pasientene---Ketil-Stordal (nedlastet 01.07.2019). 
16. Kumar A, Samavedi S, Bates AS, Coelho RF, Rocco B, Palmer K, et al. Continence outcomes of robot-assisted radical prostatectomy in patients with adverse urinary continence risk factors. BJU Int. 2015;116(5):764-70.

17. Lov 02. juni $1999 \mathrm{nr} .61 \mathrm{om}$ spesialisthelsetjenesten (spesialisthelsetjenesteloven). Kapittel 3. Tilgjengelig fra: https://lovdata.no/dokument/NL/lov/1999-07-02-61 (nedlastet 30.07.2019).

18. Skalla KA, Bakitas M, Furstenberg CT, Ahles T, Henderson JV. Patients' need for information about cancer therapy. Oncol Nurs Forum. 2004;31(2):313-9.

19. Davidson R, Mills ME. Cancer patients' satisfaction with communication, information and quality of care in a UK region. Eur J Cancer Care (Engl). 2005;14(1):83-90.

20. Morland E. Min jobb som uroterapeut. «Blæra er et vanedyr». Sykepleien. 2013;101(3):42.

21. Larsen TFW, Frugård J, Dragesund T. Urinlekkasje og bekkenbunnstrening også for menn. Fysioterapeuten. 2007; (2):13-7.

22. Walker JA. What is the effect of preoperative information on patient satisfaction? Br J Nurs. 2007;16(1):2732.

23. Bratlie MS. Pasienttilfredshet som kvalitetsindikator. (Masteroppgave.) Oslo: Universitetet i Oslo, Det Medisinske fakultet, Institutt for helse og samfunn; 2015.

24. Shirley ED, Sanders JO. Patient satisfaction: Implications and predictors of success. J Bone Joint Surg Am. 2013;95(10):e69.

25. Chow A, Mayer EK, Darzi AW, Athanasiou T. Patientreported outcome measures: the importance of patient satisfaction in surgery. Survey 146. 2009;(3):435-43.

26. Jaeger J, Weißbach L, Pfaff H, Ernstmann N. Localized prostate cancer patients ' information in urology outpatients' practice - result of a Nationwide study in Germany. Journal of Cancer Therapy. 2013;4(4A):3-10. 
27. Bjertnaes OA, Sjetne IS, Iversen HH. Overall patient satisfaction with hospitals: effects of patient-reported experiences and fulfilment of expectations. BMJ Quality \& Safety. 2012;21(1):39-46.

28. Watts S, Leydon G, Birch B, Prescott P, Lai L, Eardley S. Depression and anxiety in prostate cancer: a systematic review and meta-analysis of prevalence rates. BMJ open. 2014;4(3):e003901.

29. Trofimenko V, Myers JB, Brant WO. Post-prostatectomy incontinence: How common and bothersome is it really? Sex Med Rev. 2017;5:536-43. 